\title{
Disease burden and associated risk factors for metabolic syndrome among adults in Ethiopia
}

\author{
Samrawit Solomon ${ }^{1 *}$ (D) and Wudeneh Mulugeta ${ }^{2^{*}}$
}

\begin{abstract}
Background: Metabolic Syndrome (MetS) and Non-communicable diseases (NCDs) are alarmingly increasing in low-income countries. Yet, very limited is known about the prevalence and risk factors associated with MetS in Ethiopia.

Methods: A cross-sectional study was conducted among adult outpatients $(N=325)$ at St. Paul's Hospital Millennium Medical College in Addis Ababa, Ethiopia. The study was conducted in accordance with STEPwise approach of the World Health Organization. MetS was defined using modified National Cholesterol Education Program's Adult Treatment Panel III criteria. Univariate and multivariate analyses were performed.

Results: The overall prevalence of MetS was 20.3\%. Among the 325 participants, $76.9 \%$ had at least one MetS components. Reduced high-density lipoprotein cholesterol was the most common MetS component at 48.6\%, followed by elevated blood pressure at 36.3\%, and elevated fasting glucose at 32.6\%. Older age (odds ratio $[O R]=4.15 ; 95 \%$ confidence interval $[\mathrm{Cl}]=1.43-12.04)$, Amhara ethnicity $(\mathrm{OR}=2.36 ; 95 \% \mathrm{Cl}=1.14-4.88)$, overweight status $(\mathrm{OR}=2.21 ; 95 \% \mathrm{Cl}=1.03-4.71)$, higher income $(\mathrm{OR}=3.31 ; 95 \% \mathrm{Cl}=1.11-9.84)$ and higher education levels $(\mathrm{OR}=2.19 ; 95 \% \mathrm{Cl}=1.05-4.59)$ were risk factors for MetS.

Conclusion: The disease burden of MetS among Ethiopians is high, and is associated with age, weight, income, education and ethnicity. Comprehensive screening and assessment of MetS is needed along with effective preventive and treatment strategies in low-income countries, such as Ethiopia.
\end{abstract}

\section{Background}

Non-communicable diseases (NCDs) are the leading causes of death globally, killing more people each year than all other causes combined [1]. Nearly $85 \%$ of the global premature deaths associated with NCDs occur in low- and middle-income countries [1]. If the current growing burden of NCDs continues, the cumulative loss to global economy has been estimated to reach $\$ 47$ trillion by 2030 [2]. Currently, one of the leading global public-health challenges is metabolic syndrome (MetS), which includes abdominal obesity, dyslipidemia, hyperglycemia, and hypertension. MetS has been linked to the

\footnotetext{
* Correspondence: Samrawit.solomon@sphmmc.edu.et; nigistmy@yahoo.com; wudmul@gmail.com; wmulugeta@cha.harvard.edu

${ }^{1}$ Department of Public Health, St. Paul's Hospital Millennium Medical College, Addis Ababa, Ethiopia

2Department of Medicine, Harvard Medical School, Cambridge Health Alliance, 454 Broadway; Revere, Cambridge, MA, USA
}

risk of developing cardiovascular disease (CVD) and type 2 diabetes mellitus [3]. Visceral adiposity and insulin resistance are thought to be the underlying mechanisms for MetS [3].

Most of the studies on MetS have been conducted in North America, Europe, and Asia [4-6]. As a result, very limited is known about the prevalence and risk factors of metabolic syndrome among sub-Saharan African population. The few studies conducted in sub-Saharan Africa show the prevalence of metabolic syndrome is rapidly approaching that of the developed nations $[7,8]$. This could be because of adaptations of unhealthy Western diet and lifestyle, as well as tobacco use, and use of antiHIV drugs in those areas $[9,10]$. Recently, the rapid economic growth along with the aging population and the sedentary lifestyle in sub-Saharan countries like Ethiopia has increased the NCDs epidemics $[8,11,12]$. 
Although there have been few other studies in subSaharan Africa, this is one of the first studies to examine disease burden and risk factors for Metabolic Syndrome at a major referral hospital in Ethiopia in a general outpatient setting [13, 14]. Given this gap in the literature, and given the importance in developing health promotion and disease prevention programs in low- and middle-income countries, we examined the prevalence and risk factors of metabolic syndrome and its components in Ethiopia.

\section{Methods}

\section{Study design and participants}

This hospital based cross-sectional study was conducted from September 2017 to October 2017 at the outpatient departments at St. Paul's Hospital Millennium Medical College (SPHMMC) in Addis Ababa, the capital city of Ethiopia. SPHMMC is one of the largest teaching and referral hospitals in the country with inpatient capacity of more than 1000 beds, and an average of 2000 emergency and outpatient clients daily. We investigated patients from outpatient department not in chronic follow-up OPD's (where patients are known hypertensive, diabetic or other chronic disease follow-up patients) because those are patients who presented to St Paul's hospital millennium medical college with different types of complaints. The inclusion criteria were all eligible adult patients coming to outpatient department at SPHMMC during the study period. The exclusion criteria were patients at departments other than the outpatient department at SPHMMC, such those who were getting care inpatient, and those patients who did not fast overnight for at least $8 \mathrm{~h}$. Patients unable or unwilling to provide informed consent to participate in the study in Amharic or Oromifa were also excluded. However, all of the potential study participants approached spoke Amharic and/or Oromifa languages. The study was conducted in accordance with a modified STEPwise approach to non-communicable disease risk factor surveillance of the World Health Organization (WHO), which includes questionnaire, physical and biochemical measurements [15]. Ethical clearance was obtained from Institutional Review Board of SPHMMC, Addis Ababa, Ethiopia and an official letter of permission was obtained from the research directorate. Patients' confidentiality was kept throughout the study and names of individuals was not included in the study at any phase. Written consent was obtained before inclusion into the study after announcing the details of the study including the benefits and risks.

\section{Data collection and variable specification}

Participants were interviewed by a trained health officer and a nurse using the modified WHO STEPwise questionnaire. The questionnaire was in English, translated into Amharic and Oromifa, which are common languages in Ethiopia, and then translated back into English.

Trained staff health officers collected blood samples and standard anthropometric measurements. Manual blood pressure (BP) was measured with participants sitting, after resting for at least $5 \mathrm{~min}$. The waist circumference was taken at the borderline between the lower boundary of the last palpable rib and the top of the iliac crest. Body mass index (BMI) was calculated by dividing weight in kilograms by height squared in meters $(\mathrm{kg} / \mathrm{m} 2)$ with regular monitoring and adjustment of the beambalance. Weight was categorized using the National Heart, Lung, and Blood Institute's classification system.

After an 8-h overnight fasting, blood specimen was collected from every participant to determine the fasting blood sugars and lipid profiles in the college's clinical chemistry laboratory. Triglyceride (TG) concentrations were measured by standard enzymatic assays using glycerol phosphate oxidase method. High-density lipoprotein cholesterol (HDL-C) was determined after sample pretreatment with a precipitating reagent and centrifugation. Participants' fasting blood glucose (FBG) were determined using glucose oxidase method. Normal and pathological quality control materials were run every day to detect any analytical errors and validate the laboratory values. Standard operating procedures for all the quality assurance phases were utilized.

Determination of Metabolic Syndrome (MetS): Metabolic Syndrome was defined using the modified National Cholesterol Education Program's Adult Treatment Panel III criteria (NCEP ATP III), and a joint definition that was agreed upon by several organizations (International Diabetes Federation Task Force on Epidemiology and Prevention; National Heart, Lung, and Blood Institute; American Heart Association; World Heart Federation; International Atherosclerosis Society; and International Association for the Study of Obesity) [16, 17]. In accordance with the NCEP ATP III criteria, subjects were classified as having Met $S$ if participants have three or more of the following risk factors: (1) Abdominal obesity (waist circumference $>102 \mathrm{~cm}$ in men and $>88 \mathrm{~cm}$ in women) (2) Elevated triglyceride (TG $\geq 150 \mathrm{mg} / \mathrm{dL}$ ) (3) Reduced HDL-C $(<40 \mathrm{mg} / \mathrm{dL}$ in men and $<50 \mathrm{mg} / \mathrm{dL}$ in women) or drug treatment (4) High blood pressure $(\geq 130 / 85 \mathrm{mmHg})$ or drug treatment and (5) fasting blood glucose $(\geq 110 \mathrm{mg} / \mathrm{dL})$ or drug treatment $[16,17]$. In accordance with the International Diabetes Federation (IDF) criteria, subjects were classified as having MetS if a participant has abdominal obesity (defined as waist circumference of $\geq 94 \mathrm{~cm}$ for men and $\geq 80 \mathrm{~cm}$ women) plus two of any of the following risk factors: (1) Elevated triglyceride ( $\geq 150 \mathrm{mg} / \mathrm{dL})$ (2) Reduced HDL-C $(<40 \mathrm{mg} / \mathrm{dL}$ 
in men and $<50 \mathrm{mg} / \mathrm{dL}$ in women) or drug treatment (3) Elevated blood pressure (systolic BP $\geq 130$ or diastolic BP $\geq 85 \mathrm{mmHg}$ ) or drug treatment (4) Elevated fasting blood glucose $(\geq 100 \mathrm{mg} / \mathrm{dL})$ or drug treatment [18].

\section{Statistical analyses}

Frequency distributions of socio-demographic and behavioral characteristics of study participants were examined. The overall prevalence and prevalence estimates of metabolic syndrome across socio-economic groups were calculated separately based on gender. Chi-square tests were used to assess differences in the distributions of categorical variables.

Univariate and multivariate binary logistic regression analyses were performed to examine factors associated with metabolic syndrome. The regression models were built with metabolic syndrome as the outcome variable after adjusting for covariates. Covariates were included in the final regression model using $p$-value $<0.2$ as a cut-off, as well as based on priori and our conceptual framework. Adjusted odds ratios (AOR) with 95\% confidence intervals $(95 \% \mathrm{CI})$ were used to determine the magnitude of associations among metabolic syndrome and various potential risk factors. Two-tailed statistical significance was assessed at $\alpha<0.05$. All the analyses were conducted in 2018 using statistical software SAS 9.4 (SAS Institute Inc., Cary, NC).

\section{Results}

Basic demographic characteristics of the participants are provided in Table 1 . Out of the 325 study participants, 155 (47.7\%) were men and 170 (52.3\%) were women. Nearly a quarter $(24.6 \%)$ of the participants was aged 51 years or older, whilst $33.2 \%$ were younger than 30 years of age. The majority of participants reported to be married (62.8\%) and reside in Addis Ababa (63.6\%). Most participants reported to be Oromo (44.7\%) in ethnicity with education levels of primary school or less (59.7\%) and non-government employment status (48.0\%). The prevalence of underweight, overweight, and obese were $10.4,18.8$, and $3.3 \%$, respectively.

Table 1 Basic demographic characteristics of adult outpatients $(N=325)$ at St. Paul's Hospital Millennium Medical College in Addis Ababa, Ethiopia

\begin{tabular}{|c|c|c|c|c|c|}
\hline Variable & & Total $N=325(\%)$ & Men $N=155(\%)$ & Women $N=170(\%)$ & $p$-value \\
\hline \multirow[t]{3}{*}{ Age, years } & $<30$ & $108(33.2)$ & $43(27.7)$ & $65(38.2)$ & 0.013 \\
\hline & $30-50$ & $137(42.2)$ & $63(40.7)$ & $74(43.5)$ & \\
\hline & $\geq 51$ & $80(24.6)$ & 49 (31.6) & $31(18.2)$ & \\
\hline \multirow[t]{3}{*}{ Region } & Addis Ababa & 199 (63.6) & $97(63.4)$ & $102(63.8)$ & 0.646 \\
\hline & Oromia & $78(24.9)$ & $36(23.5)$ & $42(26.4)$ & \\
\hline & Others & $36(11.5)$ & $20(13.1)$ & $16(10.0)$ & \\
\hline \multirow[t]{3}{*}{ Ethnicity } & Oromo & $142(44.7)$ & $70(46.1)$ & $72(43.4)$ & 0.851 \\
\hline & Amhara & $103(32.4)$ & $47(30.9)$ & $56(33.7)$ & \\
\hline & Others & $73(22.9)$ & $35(23.0)$ & $38(22.9)$ & \\
\hline \multirow[t]{3}{*}{ Marital status } & Single & $77(23.7)$ & $43(27.7)$ & $34(20.0)$ & 0.0004 \\
\hline & Married & $204(62.8)$ & $103(66.5)$ & $101(59.4)$ & \\
\hline & Divorced/ widowed & $44(13.5)$ & $9(5.8)$ & $35(20.6)$ & \\
\hline \multirow[t]{3}{*}{ Income, birr } & $<2000$ & $44(36.7)$ & 19 (30.7) & $25(43.1)$ & 0.322 \\
\hline & $2000-4000$ & $44(36.7)$ & $26(41.9)$ & $18(31.0)$ & \\
\hline & $\geq 4000$ & $32(26.7)$ & $17(27.4)$ & $15(25.9)$ & \\
\hline \multirow[t]{2}{*}{ Education } & Primary schools or less & $178(59.7)$ & $78(53.8)$ & $100(65.4)$ & 0.114 \\
\hline & Secondary school or more & $120(40.3)$ & $67(46.2)$ & $53(34.6)$ & \\
\hline \multirow[t]{3}{*}{ Occupation } & Government employees & $50(15.4)$ & $25(16.3)$ & $25(14.7)$ & $<0.0001$ \\
\hline & Other employees/ students & $156(48.0)$ & $93(60.0)$ & $63(37.1)$ & \\
\hline & Unemployed & 119 (36.6) & $37(23.9)$ & $82(48.2)$ & \\
\hline \multirow[t]{4}{*}{ Weight, BMl in kg/m2 } & Underweight $(<18.5)$ & $32(10.4)$ & $13(8.7)$ & $19(12.0)$ & 0.397 \\
\hline & Normal (18.5-24.9) & $208(67.5)$ & 107 (71.3) & $101(63.9)$ & \\
\hline & Overweight (25.0-29.9) & $58(18.8)$ & $27(18.0)$ & $31(19.6)$ & \\
\hline & Obese $(\geq 30.0)$ & $10(3.3)$ & $3(2.0)$ & $7(4.4)$ & \\
\hline
\end{tabular}


Table 2 Behavioral and lifestyle characteristics of adult outpatients $(N=325)$ at St. Paul's Hospital Millennium Medical College in Addis Ababa, Ethiopia

\begin{tabular}{|c|c|c|c|c|c|}
\hline Variable & & Total $N=325(\%)$ & Men $N=155(\%)$ & Women $N=170(\%)$ & $p$-value \\
\hline Alcohol use & & $106(32.6)$ & $63(40.7)$ & $43(25.3)$ & 0.003 \\
\hline Tobacco use & & $12(3.7)$ & $12(7.7)$ & $0(0.0)$ & 0.0002 \\
\hline Khat use & & $33(10.3)$ & $30(19.5)$ & $3(1.8)$ & $<0.0001$ \\
\hline Physical activity at work & & $105(33.6)$ & $49(33.1)$ & $56(33.9)$ & 0.876 \\
\hline \multirow[t]{2}{*}{ Number of days with physical activity at work } & $<5$ days/week & $261(80.3)$ & $118(76.1)$ & $143(84.1)$ & \multirow[t]{2}{*}{0.071} \\
\hline & $\geq 5$ days/week & $64(19.7)$ & $37(23.9)$ & $27(15.9)$ & \\
\hline Doing exercise / leisure physical activity & & $16(4.9)$ & $9(5.9)$ & $7(4.1)$ & 0.473 \\
\hline Walking/ bicycle for transportation & & $194(60.3)$ & $92(60.1)$ & $102(60.4)$ & 0.967 \\
\hline Adding salt before or as eating & & $230(71.0)$ & $108(70.1)$ & $122(71.7)$ & 0.746 \\
\hline \multirow[t]{3}{*}{ Type of oil used } & None & $129(39.9)$ & $58(37.9)$ & $71(41.8)$ & \multirow[t]{3}{*}{0.525} \\
\hline & Vegetable oil & $133(41.2)$ & $68(44.4)$ & $65(38.2)$ & \\
\hline & Other oil/ fat & $61(18.9)$ & $27(17.7)$ & $34(20.0)$ & \\
\hline \multirow[t]{3}{*}{ Number of days fruits or vegetables were eaten } & $\geq 5$ days/week & $113(34.8)$ & $54(34.8)$ & $59(34.7)$ & \multirow[t]{3}{*}{0.988} \\
\hline & 2-4 days/week & $125(38.5)$ & $59(38.1)$ & $66(38.8)$ & \\
\hline & $<2$ days/week & $87(26.8)$ & $42(27.1)$ & $45(26.5)$ & \\
\hline \multirow[t]{2}{*}{ Number of fruits or vegetable servings } & $\geq 5$ servings/day & $5(1.5)$ & $3(1.9)$ & $2(1.2)$ & \multirow[t]{2}{*}{0.579} \\
\hline & $<5$ servings/day & $320(98.5)$ & $152(98.1)$ & $168(98.8)$ & \\
\hline
\end{tabular}

Table 2 shows behavioral and lifestyle characteristics of the study population. Alcohol, Khat, and tobacco use were reported by $32.6,10.3$, and $3.7 \%$ of the participants, respectively. Approximately a third (33.6\%) of the participants reported a moderate or vigorous level of physical activity at work, while only $4.9 \%$ reported regular exercise or leisure physical activity. However, the majority (60.3\%) used walking/ bicycle for transportation. Most (71.0\%) reported adding salt before or during eating meals, and only $1.5 \%$ reported eating 5 or more servings of fruits and vegetables a day.

Alcohol use in the past year; current tobacco use; ever used Khat; physical activities: moderate or vigorous work or leisure/ recreational activities/ exercise; adding salt always, often or sometimes vs rarely or never.
Table 3 shows frequency of Metabolic Syndrome (MetS) and MetS components. The prevalence of MetS according to the modified NCEP-ATP III criteria was $20.3 \%$ (18.1\% among men and $22.4 \%$ among women). The most common MetS component was reduced highdensity lipoprotein cholesterol (HDL-C) at $48.6 \%$, followed by elevated blood pressure at $36.3 \%$, and elevated fasting glucose at $32.6 \%$. Nearly a quarter $(24.0 \%)$ of participants had elevated Triglyceride levels, whilst $10.5 \%$ had abdominal obesity according to the modified NCEP-ATP III criteria.

Table 4 shows $76.9 \%$ of the participants had at least one MetS components, $46.8 \%$ had at least two MetS components, $20.3 \%$ had at least three MetS components, $6.8 \% \mathrm{had}$ at least four MetS components, and 1.2\% had

Table 3 Frequency of metabolic syndrome (MetS) and components among adult outpatients $(N=325)$ at St. Paul's Hospital Millennium Medical College in Addis Ababa, Ethiopia

\begin{tabular}{|c|c|c|c|c|}
\hline Parameters & Total $N=325(\%)$ & Men $N=155(\%)$ & Women $N=170(\%)$ & $p$-value \\
\hline Metabolic syndrome by NCEP-ATP III & $66(20.3)$ & $28(18.1)$ & $38(22.4)$ & 0.337 \\
\hline Metabolic syndrome by IDF & $28(8.6)$ & $3(1.9)$ & $25(14.7)$ & $<0.001$ \\
\hline Abdominal obesity by NCEP-ATP III & $34(10.5)$ & $2(1.3)$ & $32(18.8)$ & $<0.001$ \\
\hline Abdominal obesity by IDF & $63(19.4)$ & $4(2.6)$ & $59(34.7)$ & $<0.001$ \\
\hline Elevated fasting glucose & $106(32.6)$ & $57(36.8)$ & $49(28.8)$ & 0.126 \\
\hline Elevated Triglycerides & $78(24.0)$ & $40(25.8)$ & $38(22.4)$ & 0.467 \\
\hline Elevated blood pressure & $118(36.3)$ & $65(41.9)$ & $53(31.2)$ & 0.044 \\
\hline Reduced HDL-C & $158(48.6)$ & $64(41.3)$ & $94(55.3)$ & 0.012 \\
\hline
\end{tabular}

NCEP ATP III: modified National Cholesterol Education Program's Adult Treatment Panel III criteria; IDF: International Diabetes Federation; HDL-C: High-density lipoprotein cholesterol 
Table 4 Number of metabolic syndrome (MetS) components by gender according to the modified NCEP-ATP III criteria among adult outpatients $(N=325)$ at St. Paul's Hospital Millennium Medical College in Addis Ababa, Ethiopia

\begin{tabular}{llll}
\hline Number of MetS components & Total $N=325(\%)$ & Men $N=155(\%)$ & Women N=170 (\%) \\
\hline 0 & $75(23.1)$ & $35(22.6)$ & $40(23.5)$ \\
1 & $98(30.2)$ & $48(30.9)$ & $50(29.4)$ \\
2 & $86(26.5)$ & $44(28.4)$ & $42(24.7)$ \\
3 & $44(13.5)$ & $22(14.2)$ & $22(12.9)$ \\
4 & $18(5.5)$ & $4(2.6)$ & $14(8.2)$ \\
5 & $4(1.2)$ & $2(1.3)$ & $2(1.2)$ \\
\hline
\end{tabular}

all five MetS components in accordance with the modified NCEP-ATP III criteria.

Factors associated with MetS are summarized in Table 5. Compared to those younger than 30 years of age, those aged 51 years or older (adjusted odds ratio $[\mathrm{AOR}]=4.15$; 95\% confidence interval $[\mathrm{CI}]=1.43-12.04)$, Amhara ethnicity versus Oromo ethnicity $(\mathrm{AOR}=2.36 ; 95 \% \mathrm{CI}=$ 1.14-4.88), and those who were overweight vs normal weight $(\mathrm{AOR}=2.21 ; 95 \% \mathrm{CI}=1.03-4.71)$ were associated with MetS. Study participants with higher income vs low income levels (AOR $=3.31 ; 95 \% \mathrm{CI}=1.11-9.84)$, and higher education level of secondary school or more vs primary

Table 5 Prevalence and factors associated with Metabolic Syndrome (MetS) according to the modified NCEP-ATP III criteria, using logistic regression, among adult outpatients $(N=325)$ at St. Paul's Hospital Millennium Medical College in Addis Ababa, Ethiopia

\begin{tabular}{|c|c|c|c|c|c|c|}
\hline Variables & & MetS n(\%) & Crude OR (95\% Cl) & $p$-value & Adjusted OR (95\% Cl) & $p$-value \\
\hline \multirow[t]{2}{*}{ Sex } & Male & $28(18.1)$ & 1.00 & - & 1.00 & - \\
\hline & Women & $38(22.4)$ & $1.31(0.76,2.25)$ & 0.34 & $1.88(0.93,3.80)$ & 0.08 \\
\hline \multirow[t]{3}{*}{ Age, years } & $<30$ & $9(8.3)$ & 1.00 & - & 1.00 & - \\
\hline & $30-50$ & $29(21.2)$ & $1.10(0.64,1.89)$ & 0.74 & $1.88(0.72,4.87)$ & 0.19 \\
\hline & $\geq 51$ & $28(35.0)$ & $2.93(1.65,5.21)$ & 0.0002 & $4.15(1.43,12.04)$ & 0.01 \\
\hline \multirow[t]{3}{*}{ Ethnicity } & Oromo & $21(14.8)$ & 1.00 & - & 1.00 & - \\
\hline & Amhara & $30(29.1)$ & $2.12(1.22,3.70)$ & 0.01 & $2.36(1.14,4.88)$ & 0.02 \\
\hline & Others & $14(19.2)$ & $0.91(0.47,1.76)$ & 0.79 & $1.84(0.78,4.37)$ & 0.17 \\
\hline \multirow[t]{3}{*}{ Marital status } & Single & $7(9.1)$ & 1.00 & - & 1.00 & - \\
\hline & Married & 44 (21.6) & $1.24(0.70,2.19)$ & 0.46 & $1.37(0.49,3.82)$ & 0.55 \\
\hline & Divorced/ widowed & $15(34.1)$ & $2.33(1.17,4.67)$ & 0.02 & $1.95(0.65,6.85)$ & 0.29 \\
\hline \multirow[t]{3}{*}{ Income, birr } & $<2000$ & $11(25.0)$ & 1.00 & - & 1.00 & - \\
\hline & $2000-4000$ & $11(25.0)$ & $1.37(0.65,2.88)$ & 0.41 & $2.37(0.93,6.05)$ & 0.07 \\
\hline & $\geq 4000$ & $9(28.1)$ & $1.62(0.71,3.69)$ & 0.25 & $3.31(1.11,9.84)$ & 0.03 \\
\hline \multirow[t]{2}{*}{ Education } & Primary school or less & $30(16.9)$ & 1.00 & - & 1.00 & - \\
\hline & Secondary school or more & $31(25.8)$ & $1.72(0.98,3.03)$ & 0.06 & $2.19(1.05,4.59)$ & 0.04 \\
\hline \multirow[t]{3}{*}{ Occupation } & Other employees/ students & $26(16.7)$ & 1.00 & - & 1.00 & - \\
\hline & Government employees & $10(20.0)$ & $0.98(0.46,2.08)$ & 0.95 & $0.46(0.16,1.31)$ & 0.14 \\
\hline & Unemployed & $30(25.2)$ & $1.59(0.92,2.75)$ & 0.09 & $1.18(0.58,2.40)$ & 0.64 \\
\hline \multirow[t]{4}{*}{ Weight, BMI in kg/m2 } & Normal (18.5-24.9) & $33(15.9)$ & 1.00 & - & 1.00 & - \\
\hline & Underweight(< 18.5) & $4(12.5)$ & $0.53(0.18,1.57)$ & 0.25 & $0.82(0.23,2.86)$ & 0.75 \\
\hline & Overweight (25.0-29.9) & $21(36.2)$ & $2.80(1.50,5.23)$ & 0.001 & $2.21(1.03,4.71)$ & 0.04 \\
\hline & Obese $(\geq 30.0)$ & $4(40.0)$ & $2.72(0.75,9.94)$ & 0.13 & $1.65(0.35,7.90)$ & 0.53 \\
\hline \multirow[t]{2}{*}{ Adding salt before or during eating } & No & $27(28.7)$ & 1.00 & - & 1.00 & - \\
\hline & Yes & $38(16.5)$ & $0.49(0.28,0.87)$ & 0.01 & $0.59(0.31,1.13)$ & 0.11 \\
\hline \multirow[t]{2}{*}{ Doing exercise } & Yes & $1(6.3)$ & 1.00 & - & 1.00 & - \\
\hline & No & $64(20.9)$ & $0.20(0.03,1.94)$ & 0.19 & $0.18(0.01,3.95)$ & 0.28 \\
\hline
\end{tabular}


school or less $(\mathrm{AOR}=2.19 ; 95 \% \mathrm{CI}=1.05-4.59)$ were also associated with MetS. We found those with higher level of education had higher weight status, yet they also engaged in more exercise than those with lower level of education (Appendix).

\section{Discussion}

This study was conducted to assess the burden of metabolic syndrome and to identify associated risk factors among St Paul's Hospital Millennium Medical College outpatient department in Addis Ababa, Ethiopia. The findings from this study confirm high prevalence of MetS at $20.3 \%$ among adults in Ethiopia, according to the modified NCEP-ATP III criteria. The study found the most common MetS component was reduced high-density lipoprotein cholesterol (HDL-C) at $48.6 \%$, followed by elevated blood pressure at $36.3 \%$, and elevated fasting glucose at $32.6 \%$. Study participants with advanced age, higher income and higher education level of secondary school or more had higher risk of MetS. Furthermore, Amhara ethnicity $(\mathrm{OR}=2.36 ; 95 \% \mathrm{CI}=1.14-4.88)$, and overweight status $(\mathrm{OR}=2.21 ; 95 \% \mathrm{CI}=1.03-4.71)$ were associated with MetS.

The prevalence of MetS according to the modified NCEP-ATP III criteria was a bit lower (20.3\%) than that of a study done at Jimma University Teaching Hospital, in Southwest of Ethiopia, which was $26.2 \%$ and in this study the prevalence in men and women was 18.1 and $22.4 \%$, respectively, which is also comparable with that of the results from Jimma University where MetS was twice as likely to occur in females as in males [19]. This can be explained because of the similarity in the nature of the study population where they are patients visiting the outpatient department in a referral hospital. The slightly lower prevalence of MetS in our study could be attributed to younger study participants as well as regional differences compared to the study at Jimma University [19]. Other hospital based studies in Ethiopia showed higher prevalence of MetS, but they were conducted solely in hypertensive patients $[13,20]$. As expected, the overall prevalence of metabolic syndrome in our study populations was higher than prior community based studies conducted in Addis Ababa and nationally (12.5 and $4.8 \%$, respectively) [14, 21].

The most common MetS component was reduced high-density lipoprotein cholesterol (HDL-C), followed by elevated blood pressure and elevated fasting glucose which is similar with the study in Jimma where hypertension, hyperglycemia, and low HDL-cholesterol are predominant components of Mets but the rate of low density lipoprotein is higher in this study which can be explained by high rate of abdominal obesity and overweight [19]. The study found abdominal obesity was higher among men than women, which is consistent

\section{Appendix}

Table $\mathbf{6}$ Income and education levels by weight, physical activity and smoking status of adult outpatients $(N=325)$ at St. Paul's Hospital Millennium Medical College in Addis Ababa, Ethiopia

\begin{tabular}{|c|c|c|c|c|c|c|}
\hline \multicolumn{2}{|c|}{ BMI category in kg/m2 (\%) } & $<18.5$ & $18.5-24.9$ & $25.0-29.9$ & $\geq 30.0$ & $p$-value \\
\hline \multirow[t]{3}{*}{ Income, birr } & $<2000$ & 69.1 & 7.1 & 16.6 & 7.1 & 0.834 \\
\hline & $2000-4000$ & 72.5 & 7.5 & 17.5 & 2.5 & \\
\hline & $\geq 4000$ & 66.6 & 3.3 & 26.7 & 3.3 & \\
\hline \multirow[t]{2}{*}{ Education } & Primary schools or less & 73.1 & 10.1 & 14.9 & 1.8 & 0.010 \\
\hline & Secondary school or more & 57.0 & 9.7 & 27.2 & 6.1 & \\
\hline \multicolumn{2}{|c|}{ Regular exercise/ physical activity (\%) } & Yes & & No & & $p$-value \\
\hline \multirow[t]{3}{*}{ Income, birr } & $<2000$ & 4.8 & & 95.2 & & 0.136 \\
\hline & $2000-4000$ & 4.6 & & 95.4 & & \\
\hline & $\geq 4000$ & 15.6 & & 84.4 & & \\
\hline \multirow[t]{2}{*}{ Education } & Primary schools or less & 2.8 & & 97.2 & & 0.031 \\
\hline & Secondary school or more & 8.5 & & 91.5 & & \\
\hline \multicolumn{2}{|c|}{ Tobacco use (\%) } & Yes & & No & & $p$-value \\
\hline \multirow[t]{3}{*}{ Income, birr } & $<2000$ & 4.6 & & 95.4 & & 0.834 \\
\hline & $2000-4000$ & 2.3 & & 97.7 & & \\
\hline & $\geq 4000$ & 3.1 & & 96.9 & & \\
\hline \multirow[t]{2}{*}{ Education } & Primary schools or less & 5.6 & & 94.4 & & 0.088 \\
\hline & Secondary school or more & 1.7 & & 98.3 & & \\
\hline
\end{tabular}

Appendix shows the relationship of weight status by BMI categories and levels of education with physical activity and smoking status among the study participants 
with the findings of other studies and global trends [14, $19,22]$.

In our study, compared to those younger than 30 years of age, those aged 51 years or older (adjusted odds ratio $[\mathrm{AOR}]=4.15 ; 95 \%$ confidence interval $[\mathrm{CI}]=1.43-12.04$ ) and those who were overweight vs normal weight $(\mathrm{AOR}=2.21 ; 95 \% \mathrm{CI}=1.03-4.71)$ were associated with MetS. This result is comparable with the national survey done in Ethiopia where individuals aged 65 years and older were at increased risk of developing the metabolic abnormality but lack of physical activity was not associated with MetS in this study as in most of similar studies in Ethiopia [20, 21]. The lack of association between MetS and exercise in our study, as well as other similar studies, is likely due to lack of power in light of the low overall prevalence of exercise or leisure physical activity among the population.

Similar to other studies, we found income and education levels are associated with MetS [13, 20, 23, 24]. Our findings showed MetS was associated with participants with higher income vs low income levels $(\mathrm{AOR}=3.31 ; 95 \% \mathrm{CI}=$ 1.11-9.84), and higher education level of secondary school or more vs primary school or less $(\mathrm{AOR}=2.19 ; 95 \% \mathrm{CI}=$ 1.05-4.59). The relationships are likely different between high-income [23] and low-income countries [13, 24]. As those with lower income and education levels in developing countries, likely do more physical and labor intensive types of jobs, while those with higher income and education levels could be less physically active and may also be adapting unhealthy lifestyles [13, 24].

Our study has several strengths which powered to make adequate subgroup comparisons; it is also one of the first studies to examine MetS and its risk factors at a major referral hospital in Ethiopia, including a diverse general outpatient population. Our study has several limitations. First, as a cross-sectional study, there is lack of temporality and causality in the study. Second, social desirability biases may lead to underestimating some of the lifestyle and behavioral questions, such as smoking and alcohol consumptions. Third, as a hospital-based study, generalizability of the study findings to the broader Ethiopian population is limited. Despite these limitations, the study makes significant contribution and fills a substantial gap in the current literature. Further multicenter investigations are needed to understand the underlying reasons and modifiable risk factors behind subgroup differences in more generalizable study settings.

\section{Conclusions}

In conclusion, this study contributes to the substantial gap in the current literature regarding MetS and its risk factors in sub-Saharan Africa. There is significant disease burden of MetS among the general adult outpatients in Ethiopians. MetS risk increases with advanced age, weight status, income, education and certain ethnic groups. Comprehensive screening and assessment of MetS and its modifiable risk factors is needed along with effective preventive and treatment strategies in lowincome countries, such as Ethiopia.

\section{Abbreviations \\ AOR: Adjusted odds ratios; BMI: Body mass index; CVD: Cardiovascular disease; FBG: Fasting blood glucose; HDL-C: High-density lipoprotein cholesterol; IDF: International diabetes fe*deration; MetS: Metabolic syndrome; NCDs: Non-communicable diseases; NCEP ATP III: National Cholesterol Education Program's adult treatment panel III criteria; OR: Odds ratio; SPHMMC: St. Paul's hospital millennium medical college; \\ TG: Triglyceride; WHO: World Health Organization}

\section{Acknowledgements}

We wish to thank the participants for their role in this study as well as the St Paul's Hospital Millennium Medical College community and staff for their support and data acquisition.

\section{Authors' contributions}

Both authors (SS, WM) made substantial contributions to conception and design, or acquisition of data, or analysis and interpretation of data. Both SS and WM were involved in drafting the manuscript or revising it critically for important intellectual content. Both authors (SS, WM) have given final approval of the version to be published and agreed to be accountable for all aspects of the work in ensuring that questions related to the accuracy or integrity of any part of the work are appropriately investigated and resolved. All authors have read and approved the manuscript.

\section{Funding}

The study was funded by internal research grant from St. Paul's Hospital Millennium Medical College (SPHMMC) in Addis Ababa, Ethiopia. The authors are solely responsible for the design of the study and collection, analysis, and interpretation of data and writing of the manuscript.

\section{Availability of data and materials}

The datasets used and/or analyzed during the current study are available from the corresponding author on reasonable request.

\section{Ethics approval and consent to participate}

Ethical approval was obtained from the Institutional Review Board (IRB) of St Paul's Hospital Millennium Medical College (SPHMMC) in Addis Ababa, Ethiopia. And all of the participants signed informed consents before participating in the study.

Consent for publication

Not applicable.

Competing interests

The authors declare that they have no competing interests.

Received: 28 September 2018 Accepted: 24 September 2019 Published online: 26 October 2019

\section{References}

1. World Health Organization (WHO). Global status report on noncommunicable diseases 2014. http://www.who.int/nmh/publications/ ncd-status-report-2014/en/. Accessed 9 Sept 2018.

2. Bloom DE, Cafiero ET, Jané-Llopis E, Abrahams-Gessel S, Bloom LR, Fathima S, Feigl AB, Gaziano T, Mowafi M, Pandya A, Prettner K, Rosenberg L, Seligman B, Stein AZ, Weinstein C. The global economic burden of noncommunicable diseases. Geneva: World Economic Forum; 2011.

3. Eckel RH, Grundy SM, Zimmet PZ. The metabolic syndrome. Lancet. 2005; 365(9468):1415-28.

4. Lee CM, Huxley RM, Woodward M, et al. Comparisons of metabolic syndrome definitions in four populations of the Asia-Pacific region. Metab Syndr Relat Disord. 2008;6(1):37-46. 
5. Ford ES. Prevalence of the metabolic syndrome defined by the international diabetes federation among adults in the U.S. Diabetes Care. 2005;28(11): 2745-9.

6. Ford ES, Giles WH, Dietz WH. Prevalence of the metabolic syndrome among US adults: findings from the third National Health and nutrition examination survey. J Am Med Assoc. 2002;287(3):356-9.

7. Motala AA, Mbanya JC, Ramaiya KL. Metabolic syndrome in sub-Saharan Africa. Ethnicity Disease. 2009;19(2):S2-8.

8. Kelliny C, William J, Riesen W, Paccaud F, Bovet P. Metabolic syndrome according to different definitions in a rapidly developing country of the African region. Cardiovasc Diabetol. 2008;7:article no. 27.

9. Kamari Y, Grossman E, Oron-Herman M, et al. Metabolic stress with a high carbohydrate diet increases adiponectin levels. Horm Metab Res. 2007;39(5):384-8.

10. Mutimura E, Crowther NJ, Stewart A, Cade WT. The human immunodeficiency virus and the cardio metabolic syndrome in the developing world: an African perspective. J Cardiometabolic Syndrome. 2008;3(2):106-10.

11. Okafor $\mathrm{Cl}$. The metabolic syndrome in Africa: current trends. Indian J Endocrinol Metabolism. 2012;16(1):56-66. https://doi.org/10.4103/2230-8210.91191.

12. Vorster $\mathrm{HH}$. The emergence of cardiovascular disease during urbanisation of Africans. Public Health Nutr. 2002;5(1A):239-43.

13. Tachebele B, Abebe M, Addis Z, Mesfin N. Metabolic syndrome among hypertensive patients at University of Gondar Hospital, north West Ethiopia: a cross sectional study. BMC Cardiovasc Disord. 2014;14:177. https://doi.org/ 10.1186/1471-2261-14-177.

14. Tran A, Gelaye B, Girma B, et al. Prevalence of metabolic syndrome among working adults in Ethiopia. Int J Hypertens. 2011;2011:193719. https://doi. org/10.4061/2011/193719.

15. World Health Organization (WHO). The WHO STEPwise approach to noncommunicable disease risk factor surveillance (STEPS) 2014, http://www. who.int/ncds/surveillance/steps/en/.

16. Grundy SM, Cleeman JI, Daniels SR, Donato KA, Eckel RH, Franklin BA, Gordon DJ, Krauss RM, Savage PJ, Smith SC Jr, Spertus JA, Costa F. Diagnosis and management of the metabolic syndrome: an American Heart Association/National Heart, Lung, and Blood Institute scientific statement. Circulation. 2005;112(17):2735-52 Epub 2005 Sep 12.

17. Alberti KG, Eckel RH, Grundy SM, Zimmet PZ, Cleeman JI, Donato KA, et al. Harmonizing the metabolic syndrome: a joint interim statement of the international diabetes federation task force on epidemiology and prevention; National Heart, Lung, and Blood Institute; American Heart Association; world heart federation; international atherosclerosis society; and International Association for the Study of obesity. Circulation. 2009;120(16): 1640-5.

18. International Diabetes Federation (IDF). Diabetes Atlas, third edition, 2006. https://www.idf.org/e-library/epidemiology-research/diabetes-atlas/22-atlas-3 rd-edition.html

19. Abda E, Hamza L, Tessema F, Cheneke W. Metabolic syndrome and associated factors among outpatients of Jimma University teaching hospital. Diabetes Metabolic Syndrome Obesity. 2016;9:47-53. https://doi.org/10. 2147/DMSO.S97561.

20. Tadewos A, Egeno T, Amsalu A. Risk factors of metabolic syndrome among hypertensive patients at Hawassa University comprehensive specialized hospital, southern Ethiopia. BMC Cardiovasc Disord. 2017;17:218. https://doi. org/10.1186/s12872-017-0648-5.

21. Gebreyes YF, Goshu DY, Geletew TK, et al. Prevalence of high bloodpressure, hyperglycemia, dyslipidemia, metabolic syndrome and their determinants in Ethiopia: Evidences from the National NCDs STEPS Survey, 2015. Yang X-F, ed. PLoS ONE. 2018;13(5):e0194819. https://doi.org/10.1371/ journal.pone.0194819.

22. Ng M, Fleming T, Robinson M, Thomson B, Graetz N, Margono C, et al. Global, regional, and national prevalence of overweight and obesity in children and adults during 1980-2013: a systematic analysis for the Global Burden of Disease Study 2013. Lancet. 2014;384(9945):766-81.

23. Moore JX, Chaudhary N, Akinyemiju T. Metabolic syndrome prevalence by race/ethnicity and sex in the United States, National Health and nutrition examination survey, 1988-2012. Prev Chronic Dis. 2017;14:E24. https://doi. org/10.5888/pcd14.160287.

24. Shariff ZM, Sulaiman N, Jalil RA, Yen WC, Yaw YH, Taib MN, Kandiah M, Lin KG. Food insecurity and the metabolic syndrome among women from low income communities in Malaysia. Asia Pac J Clin Nutr. 2014;23(1):138-47. https://doi.org/10.6133/apjcn.2014.23.1.05.

\section{Publisher's Note}

Springer Nature remains neutral with regard to jurisdictional claims in published maps and institutional affiliations.

\section{Submit your next manuscript to BioMed Central and we will help you at every step:}

- We accept pre-submission inquiries

- Our selector tool helps you to find the most relevant journal

- We provide round the clock customer support

- Convenient online submission

- Thorough peer review

- Inclusion in PubMed and all major indexing services

- Maximum visibility for your research

Submit your manuscript at www.biomedcentral.com/submit
C) Biomed Central 